\title{
Tactile sensor which displays contour lines on contact
}

\section{接触時の等高楾を表示する触賞センサー}

Masahiro KOUCHI、Masayuki YAMAZAKI and Hiroshi HASHIMOTO

Faculty of Eng. Tokai Univ. Hiratuka Kitakaname 1117, Kanagawa, Japan

TEL 81-0463-58-1211. FAX 81-0463-59-2594. E-mail yamazaki@keyaki.u-tokai.ac.jp

( Received 15, November 1999 Accepted 28, February 2000)

A tactile sensor using moiretopography is developed. The sensor is composed of a Ronchi grating, a gel sheet, light scatterers, a light source and an ITV camera. Using the sensor, contour lines of an object with which the sensor touches were extracted and shape of an object in a visco-elastic object was found.

Keywords: Tactile sensor, Moiretopography, Gel, Diagnosis

\section{I.INTRODUCTION}

私たちは 5 感を使って環境の変化を捉え、それを元に行動 している。人間に似たこうした行動を機械にさせるには、5 感の役目をするセンサーがいる。中でも視覚センサーと並ん で触覚センサーに注目が集まっている。1

今までにも形式の違う多くの触覚センサーが報告されてい る。2、3そうしたセンサーの中には、接触にともなっておこ る触知対象物体の変形形状を定量的に表示できるものもある

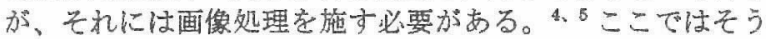
した処理を施さなくても、変形形状を等高線にして抽出でき る、モアレトポグラフィーを使った触覚センサーを提案する。

\section{II.STRUCTURE OF THE SENSOR}

センサーの構造を Fig.1 に示す。センサーはロンキー格子 (格子間䧣： $0.33 \mathrm{~mm}$ )、透明ゲルシート(厚さ： $3 \mathrm{~mm} \sim 10$ $\mathrm{mm}$ )、光の散乱体、線状光源、I T Vカメラで構成されて いる。物体との接触によって起こる接触面の変形は、モアレ トポグラフィーを使って表示される。6

\section{III.EXPERIMENTAL RESULTS}

このセンサーと物体とが接触したときに現われる映像を、 Fig. 2(a)、(b)と Fig. 3(a)、(b)に示す。Figure 2(a)はセン サーのゲルシートにくらべて十分硬い木製の球体に接触した

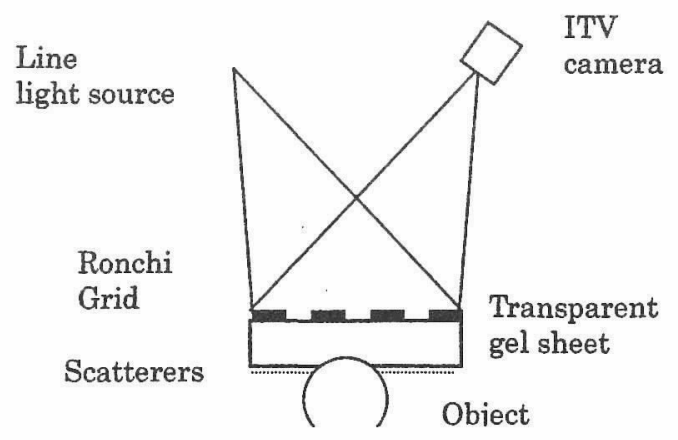

FIG. 1.Optical arrangement for the tactile sensor.

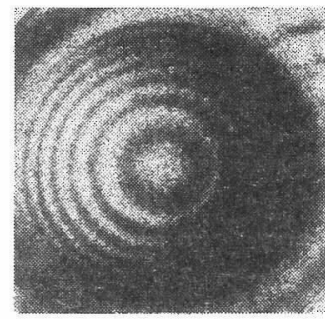

(a)

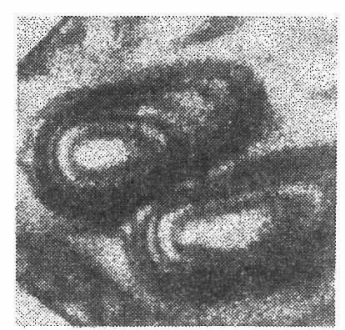

(b)
FIG.2.Tactile images. (a) Spherical object (b) Fingers

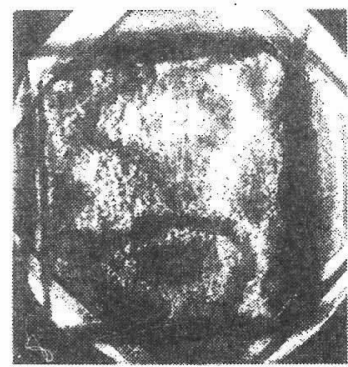

(a)

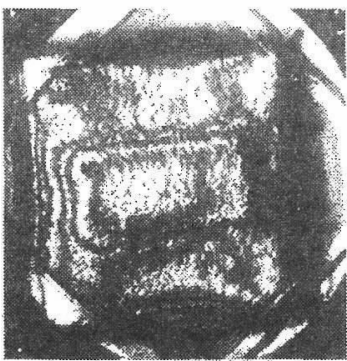

(b)
FIG. 3. Tactile images of a visco-elastic medium in which there is a rectangular solid object

ときの映像である。物体が球体であることが、等高線の形か ら、分かる。Figure2(b)は指先と接触したときの映像である。 触觉センサーの1つの利用法として触彮が考えられる。そ の可能性を検討するために、粘弾性体の内部に周辺部とは性 質の違う、直方体の粘弹体性を埋め込んで作った複合物体に 触れて、内部に埋め込んだ物体の位膡、形状が見分けられる か試した。Figure 3(a)はその物体に触れる直前の映像で、 （b）は接触後の映像である。触賞映像（b）の中央部に矩 形の模様が現われ、内部にある異物の形状を捉えている。

\section{CONCLUSION}

モアレトポグラフィーを利用して、触覚センサーを作った。 このセンサーを使うと、接触時に起こる変形量の等高線を表 
示できることや等高線の形から内部の異物を見つけられるこ とが分かった。現在、このセンサーを使って物体の粘弾性特 性のゲル剤に対する相対測定、歩行パターンの解析などを計 画している。

\section{REFERENCES}

'Nihon robotto gakkai, robotto koukaki sensa chousa houkokusho(1987)

${ }^{2}$ H. Hiraishi, N.Suzuki, M. Kaneko and K.Tanie, Nihon
Kikaigakkai ronnbun shuu (c) $55-516$ (1989) 2091.

3 H. Shinoda and S Ando, Tech Digest 10th Sensor Symposium (1991) 187.

${ }^{4}$ M. Shimojou, sensa gijyutu (1990) 31.

${ }^{5} \mathrm{M}$. Yamazaki and N. Hayashi, Toukaidaigaku kiyou kougakubu 34, (1994) 193.

${ }^{6} \mathrm{H}$. Takasaki, Ohoyo buturi49, (1980) 913.

Presented at ' 99 SAS Intelligent Symposium 